\title{
Legal Argumentation: a sociological account
}

\author{
Richard Nobles and David Schiff
}

\begin{abstract}
First of all, we need a concept of argumentation, which does not by definition include the elements of a justification, but enables us to inquire into the conditions for the possibilities and the function of reasoning. ${ }^{1}$
\end{abstract}

For jurisprudence and legal theory the nature of legal argumentation is not a trivial question. Indeed, it sits on the fault line between the major schools of Anglo-American jurisprudence. The debate between Hart and Dworkin and their respective followers can be understood in terms of whether one can adequately account for law without engaging with the nature of legal argumentation in the context of adjudication, and especially in the highest courts. ${ }^{2}$ Hart's The Concept of Law seeks to explain law, or at least the core of settled legal rules, principally by reference to the authority of existing standards without reference to the argumentative practices by which those standards are established or varied in the course of adjudication. By contrast Dworkin sought to equate law with its interpretative nature, thereby

\footnotetext{
Department of Law, Queen Mary University of London. We wish to thank our Queen Mary colleagues Katayoun Baghai, Roger Cotterrell and Susanna Lindross-Hovinheimo, and Brian Tamanaha of Washington University School of Law for their valuable comments on a draft of this article.

${ }^{1}$ Niklas Luhmann, Law as a Social System (trans KA Ziegert, Oxford University Press, 2004) 313

${ }^{2}$ That said, whether the central issues in discussion centre on legal argumentation, or legal indeterminacy, or judicial discretion is either unclear, or these potentially distinct subjects will be understood in interconnected ways.
} 
involving its argumentative practices. ${ }^{3}$ Meanwhile US legal realists and critical legal scholars join Dworkin in doubting the existence of a core of settled binding rules, but distance themselves from his account of the interpretative and argumentative practices which may resolve or restrict indeterminacy. ${ }^{4}$

This article seeks to give an account of legal argumentation using the sociological theory of Niklas Luhmann, and in particular his specific writings on this subject. ${ }^{5}$ It offers the

\footnotetext{
3 'Legal practice, unlike many other social phenomena, is argumentative.' (Ronald Dworkin, Law's
} Empire (Fontana Press, 1986) 13

${ }^{4}$ See generally Brian Leiter's excellent discussions in Naturalizing Jurisprudence (Oxford University Press, 2007) of many of the significant jurisprudential issues involved (eg 'A Note on Legal Indeterminacy', 9-12), and his advocacy of realist thinking as naturalized jurisprudence against some of the contemptuous criticisms that it has been subjected to. We recognise Leiter's contributions to realist thinking, but also wish to respond to Allan Hutchinson's claim that 'chewing historical cud' by continuing to rehearse traditional positivist, naturalist and realist discussion particularly in relation to the subject of judicial discretion inhibits 'shaping a legal theory that is relevant and responsive to the conditions and circumstances of the twenty-first century.' ('Chewing Cud: Revisiting Hart and Jurisprudence' (2014) 5 Jurisprudence 29, at 30)

${ }^{5}$ Many of Luhmann's writings are now translated into English (including translations of his last major work, Theory of Society, in 2012 and 2013) and are thus familiar to English speaking audiences and applied in many fields, including law. However his specific writing on legal argumentation has received little, if any, sustained exposition or commentary. This article attempts to fill that gap without the 'drowning' effect that is characteristic of much systems theory scholarship in which all aspects of systems theory are given priority because they do, of course, set the context for each particular subject. Such approaches are understandable in view of Luhmann's overall oeuvre which tries to reconfigure sociological enquiry - see Hans-Georg Moeller, The Radical Luhmann, (Columbia 
possibility that sociology, as developed by this author, can take the jurisprudential understanding of legal argumentation in new directions. Luhmann, best known as the author of a theory of society, neo-systems theory, wrote many articles and devoted two books to the application of his general theory to the legal system. His knowledge and interest in law was stimulated not only by his legal training and early employment in the German civil service, ${ }^{6}$ but also during his time at Cardozo Law School where he familiarised himself with the common law system and was able to consider what importance, if any, the difference between the common law and the civilian traditions had for his sociological understandings of modern law. Luhmann's analysis of legal argumentation is set out in Chapter 8 of his second book devoted to law, Law as a Social System. ${ }^{7}$ It is this chapter, in its relation to Luhmann's most detailed exposition of the operation of law as one of modern society's social sub-systems, which is the main basis for this article. Here Luhmann engages with legal theory and some other related socio-legal, literary and political theories on the nature of legal argumentation, citing works by, amongst others, MacCormick, Ladeur, Wiethölter, Alexy, Gunther, Fried, Jhering, Savigny, Levi, Derrida, Mimin, Shapiro, Dworkin, Esser, Fiss, Goodrich, Rudden, Balkin, Simmonds, Holmes, Cardozo, Pound, Stone, Atiyah and

University Press, 2012). Despite being understandable such approaches are, however, discouraging to many and one of the reasons for the relative paucity of academic engagement with Luhmann's theory in the English speaking world.

${ }^{6}$ 'Like Lorenz von Stein and Max Weber, Luhmann both studied law at university and then practised as a lawyer.' (Martin Albrow's Preface to the first English translation, in Niklas Luhmann, $A$ Sociological Theory of Law ( $2^{\text {nd }}$ English edition, trans E King-Utz and M Albrow, Routledge, 2014) xlii)

${ }^{7}$ Herefater LASS. See also, in particular, Niklas Luhmann 'Legal Argumentation: An Analysis of its Form' (1995) 58 The Modern Law Review 285. 
Summers. The chapter is both a sociological account of the function of argumentation as a legal practice, and a sociological critique of much of the jurisprudence on this topic.

Luhmann contrasts his own account of legal argumentation with 'theories of argumentation', although he does so without troubling to identify clearly which particular theorists or theories he is seeking to criticise. ${ }^{8}$ In these circumstances, we have decided that it would be easier for the readers of this journal to understand what Luhmann brings to the subject of legal argumentation if we attempt to contrast his position with that of a particular theorist on this subject likely to be known to them. The most suitable for these purposes is Ronald Dworkin (referred to in passing by Luhmann). What Luhmann has to say about 'theories of argumentation' seems clearly applicable to Dworkin's approach to this subject and its broader context of legal reasoning. And in presenting how Luhmann's analysis differs from such forms of theorising, Dworkin's work provides a clear and useful example for comparison.

Thus in the first part of this article we set out some problems with Dworkin's broad account of legal reasoning. This is not intended to be a full exploration of the many contentious issues

\footnotetext{
${ }^{8}$ Although two of the authors of theories of legal argumentation Luhmann clearly has in mind are Robert Alexy (especially the German edition of his A Theory of Legal Argumentation: The Theory of Rational Discourse as Theory of Legal Justification (trans. R Adler and N MacCormick (Clarendon Press, 1989)), and Neil MacCormick (a number of whose writings Luhmann refers to), neither is substantially focussed on, and many other theorists are used in developing his wide-ranging critique. This may be similar to what Joseph Raz describes concerning Postema's critique of 'the autonomy thesis' about law: '...by selecting features from a variety of authors so that the combined picture is in fact no one's view...' ('Postema on Law's Autonomy and Public Practical Reasons' (1998) 4 Legal Theory 1)
} 
that have been and are raised by his wide-ranging writings on this subject; that would be a different article, or at the very least an exercise that would leave little room to explore Luhmann's position. The focus of our critique of Dworkin's account of legal reasoning is the paradoxical, or we might say 'ungrounded' character of that account. In the second part of this article we introduce Luhmann's functional (sociological) method approach to the practices of legal argumentation, locating it within his analysis of the nature of modern society. The third section sets out Luhmann's description both of argumentation as a legal practice, and the 'theories of argumentation' that seek to account for it by articulating, at a more general level, the forms of reasoning exhibited within that practice. The fourth section, as an application of functionalist analysis, explores the problem for which legal argumentation is a solution: the need for both consistency and the ability to change in response to changing social conditions. In establishing this Luhmann also addresses the role played by legal argumentation in allowing the legal system to evolve. The fifth section introduces Luhmann's restatement of this problem using concepts taken from information theory: redundancy and variety. The sixth section seeks to develop our understanding of these concepts, by showing how Dworkin's account of the nature of legal reasoning and argumentation can be restated and supplemented through their use; while the seventh and last section takes the form of an assessment of what Luhmann's analysis adds to our understanding of legal argumentation's character and role, indeed whether it offers a qualitatively different understanding.

Before commencing this discussion, we need to point out that legal argumentation involves, but should not be conflated with, legal reasoning. Legal argumentation is a practice in which rival justifications are given for alternative decisions. Luhmann's discussion of legal reasoning involves a discussion of the function played by the practices of legal 
argumentation. The rationale for this is that although legal reasoning may occur in situations in which there has been no legal argumentation - as when a judge gives reasons for a decision reached without legal representations, or may occur at the level of thought, without concurrent or even future communication, in both cases what is being tested is what is convincing. And the standard of what is convincing cannot be established by an individual in isolation, but only in anticipation of its reception by other participants. Since this reception can only be evidenced by communication, ${ }^{9}$ and the only relevant communications are those which occur within the legal system, one can conclude that legal reasoning, when it takes place without legal argumentation, simply anticipates the communications that could be expected to occur within legal argumentation. ${ }^{10}$

\section{Dworkin's paradox - an example of the difficulties of} explaining legal argumentation in terms of better reasons displacing weaker ones

In Justice in Robes Dworkin extrapolates on the objectivity of legal propositions as follows: 'A proposition of law is true, I suggest, if it flows from principles of personal and political morality that provide the best interpretation of other propositions of law generally treated as true in contemporary legal practice. ${ }^{11}$ Criticism of Dworkin's position(s) has been a fruitful

\footnotetext{
${ }^{9} \mathrm{By}$ '... convincing other participants in the communication. But how could that be tested other than by communication itself.' (Luhmann, LASS 307, fn 12)

${ }^{10}$ The fuller implications of this, namely the relationship between legal reasoning and legal argumentation, are set out in section 2 .

${ }^{11}$ Harvard University Press, 2006, at 14.
} 
stimulant to jurisprudence. Whilst there is general consensus that legal decisions exhibit a significant level of consistency, Dworkin's explanation for this in terms of a process of interpretation that gravitates towards an objective 'best' answer has been challenged in many ways. These include pointing to the vagueness of his idea of fit, the possible incommensurabilty of fit and value, the ability of those 'trashing' decisions to undermine the presentation of judgments as a selection of what is 'best', etc. We do not wish to question or evaluate the strength of these or other criticisms here. Rather we wish to begin our analysis by pointing to the most persuasive aspect of Dworkin's analysis. He describes the structure of legal argumentation. Lawyers arguing points of law, and judges constructing judgments in response to the same, make reference to surrounding propositions of law. It is indeed hard to conceive of a legal argument that is free standing, in the sense that it makes no implicit or explicit connection with any other proposition that the other participants would recognise as legal. In addition, those making legal arguments certainly seem to try to present those arguments in a good light by reference to the justice of the result. Whether or not this reaches the level of moral principles is itself a matter of argument. But attempts to show that a particular legal argument results in more acceptable outcomes, or at least avoids arbitrary or wholly unreasonable ones, or that any alternative would itself lead to unreasonable results, or undermine more general expectations, are normal parts of an advocate's armoury. ${ }^{12}$ And, at

\footnotetext{
${ }^{12}$ And whilst there may be exceptions, Dworkin was also correct to claim that this is a structure of argument whereby the law is expressed as being available to be found, rather than made. When advancing their arguments in court, lawyers who admit that the existing law does not support their clients' claims, and ask for the law to be changed by the judge, are more than half-way to losing their cases. And whilst judges, who claim that the law previously found was incorrect and offer better interpretations, may succeed in changing the law, judges who admit that the law 'is' in a form that they dislike, and wish now to change, are half-way to prompting appeals.
} 
least by reference to Dworkin's own distinction between principle and policy, legal argumentation does seem to include consistent appeal to the former as potentially trumping the latter. Advocates who claim that their clients must win whilst others in indistinguishable positions must lose are unlikely to convince, ${ }^{13}$ not least because lower court judges who construct judgments in these terms are likely to encourage appeals, but also because any Supreme Court which accepts these forms of arguments would invite endless appeals based on special pleading. And none of the parties to legal disputes would be likely to concede that the other has a 'better' interpretation of what the law requires expressed only in these 'policy' terms.

Dworkin not only offers a generally accurate statement of the structure of legal arguments, he also builds his arguments, once he moved from the objective 'right answer thesis', to an aspect of legal arguments that his critics have found it hard to deny: there are some arguments that are not recognisable as good legal arguments. From this position he argued that, if there are bad legal arguments then there must be 'better' arguments, and if there are better ones, then there must, in a particular dispute, be a 'best' argument. But what makes an argument unacceptable as a legal argument, either in the sense that is not recognisably a legal argument or, even if it is recognisable as such, is clearly a poor argument in the context of a particular dispute? What provides the border of the possibly, or even probably, successful argument? To put this another way: what grounds legal arguments?

There is no obvious grounding for argumentation in law, in Dworkin's extrapolation in support of his theory of law as integrity, other than other legal arguments, or broader

\footnotetext{
${ }^{13}$ What Dworkin (n 3 above, 178-86), who associated this situation with politics, called a 'checkerboard' solution.
} 
interpretative justifications for those arguments. Indeed, the structure of legal argumentation that he identifies has elements of paradox. ${ }^{14}$ If the truth of a single legal proposition is dependent on its connection, via principles (perhaps principles of morality), to other surrounding legal propositions generally treated as true, then the truth of the propositions that are to form the foundation for this proposition must in turn be grounded in their connection to surrounding propositions generally treated as true, and so on, ad infinitum. Dworkin throughout his writings has consistently denied that positivist legal theories can provide a back stop to this process, insisting that the formal sources of law are not fixed, but are themselves open to the same interpretative processes as any other legal proposition. So, for example, for Dworkin the authority of statute as a source of law is the result of the embodiment, within the law, of democratic principles. Indeed, constitutional law is, for Dworkin, a paradigm example of legal contestation. The need for the surrounding propositions to be 'generally treated as true' suggests some kind of consensus concerning the propositions surrounding the currently contested one. But Dworkin denies that any proposition of law is immune from re-examination in terms of his statement (quoted above) of what makes a proposition of law true, and he is also on record as denying that consensus, in itself, makes something a legal proposition. His formula requires the 'best' interpretation, not the interpretation that most people, or most lawyers, or even most judges, would agree

\footnotetext{
${ }^{14}$ See Richard Nobles and David Schiff review, 'The Emperor's New Clothes' (2007) 70 The Modern Law Review, 139. By paradox is meant 'an inconsistency among nearly unrevisable principles that can be resolved only by recognizing some essential limitation of thought or language.' (Robert Koons, Paradoxes of Belief and Strategic Rationality (Cambridge University Press, 1992) 8). Where Dworkin acknowledges the need to include valid law within the justification of what can be valid law, Luhmann would describe such an account as involving a 'semantic duplication of validity as the reason for the application of norms ...' (LASS, 331)
} 
was best. The consensus surrounding propositions themselves have to be the result of a 'best' interpretation of what surrounds them. This points in turn towards a kind of holistic interpretation of the legal system, in which the determination of a single proposition requires consideration of all of the propositions in that system; the task which Dworkin set for Hercules in his original presentation of his 'right answer' and 'right to win' theses in Taking Rights Seriously, ${ }^{15}$ especially at chapters 2 and 4 . Yet there is no possibility, within the operations of the legal system, for such a holistic assessment to occur. And if, in keeping with Dworkin's later writings (and the above formula) this exercise is seen as a local one, in which the contested proposition is checked for consistency against surrounding ones, without checking further once consistency is found, there is still the problem of establishing, in any particular dispute, which propositions would be 'generally treated as true'. Lawyers do not conduct surveys to establish which legal propositions are indeed generally treated as true and, even if they did, the results of such surveys could not be introduced into legal argument for the simple reason that legal consensus is not itself a legal argument.

Dworkin himself gave some hints that the grounding of legal argumentation may be something that is amenable to sociological rather than philosophical analysis (which is not to suggest that Dworkin expressly recognised the need for sociological analysis of legal argumentation). He acknowledged that practicing lawyers will temper their commitment to integrity, in seeking to provide justifications for propositions of law, by practical constraints such as 'the need for a decision and the press of other responsibilities. ${ }^{, 16}$ And he admitted that a sense of what arguments would be possible in a particular dispute was something which a lawyer gained through experience: 'Any lawyer has built up, through education,

\footnotetext{
${ }^{15}$ Harvard University Press, 1977.

${ }^{16} \mathrm{n} 11$ above, 68
} 
training and experience, his own sense of when an interpretation fits well enough to count as an interpretation rather than an invention, and he will deploy that sense unselfconsciously. ${ }^{17}$ These concessions invite one to undertake a sociological investigation, using survey or ethnographic techniques to find out what propositions of law other lawyers have 'generally treated as true' in contemporary legal practice. And as one moves from legal philosophy into sociology, one needs to consider what sociological concepts might be appropriate for the observation of legal argumentation in these terms. Which brings us to Luhmann, a sociologist who offers us both a method and concepts with which to undertake this task and, as we hope to show, gives us a sociological account of the grounding of legal argumentation.

\section{Luhmann's functional method approach}

Luhmann offers a functionalist account of legal argumentation. Conventional functionalism, which Luhmann referred to as causal functionalism, as applied to law, analyses law whereby its structures, roles and values are explained as responses to societal needs. ${ }^{18}$ Luhmann's version of functionalism takes a somewhat divergent approach. Social phenomena are

\footnotetext{
${ }^{17} \mathrm{n} 11$ above, 15

${ }^{18}$ The closest conventional functional account of social systems to Luhmann's account is that of Talcott Parsons. His functional thesis of social systems is set out in Talcott Parsons and Neil Smelser, Economy and Society: A Study in the Integration of Economic and Social Theory (Routledge, 1956).

'Our most general proposition is that total societies tend to differentiate into sub-systems (social structures) which are specialized in each of the four primary functions. ... The sub-system goal of each ... should be defined as a primary contribution to the appropriate functional need of the total society.' (47) However, Luhmann's functional method is quite distinct, in particular because he does not account for social systems as serving particular societal needs.
} 
examined by asking: which problems are they the solution to? ${ }^{19}$ There is no assumption that the problems identified are the causes of the phenomena studied. Nor are these phenomena presumed to be unique solutions to the identified problems. Rather the assumption is that, without the observed social phenomena, or some equivalent solutions, society would not take its current form. This is an evolutionary perspective, which analyses how society could have reached its current condition in terms of problems that would have had to be overcome, treating social phenomena as possible solutions to those problems. Luhmann applied this approach $^{20}$ to analyse the problems which have needed to be solved for society to have reached its current levels of complexity. His identification of law as one of society's social systems (namely autonomous systems of communication which reproduce themselves recursively by establishing conditions whereby their own communications are connected to further communications) treats the evolution of positive law as a solution to a problem - the generation of normative expectations which have an expectation of acceptance (acceptance as meaningful expectations) without individuals sharing the kinds of common experience which, within simpler societies, might have been anticipated to generate consensus. ${ }^{21}$

\footnotetext{
${ }^{19}$ For a full statement of Luhmann's explanation, see Morten Knudsen, 'Surprised by MethodFunctional Method and Systems Theory' (2010) 11(3), Art. 12 Forum: Qualitative Social Research http://nbn-resolving.de/urn:nbn:de:0114-fqs1003122

${ }^{20}$ Knudsen, ibid 2010, thinks that this is, as a method, more often applied implicitly than explored explicitly.

${ }^{21}$ Methodological questions, not only those concerned with functional method, abound in Luhmann's writings about society and each social sub-system. To get a flavour of these large methodological issues, see his 'Preliminary Remarks on Methodology' in Theory of Society Volume 1 (trans Rhodes Barrett, Stanford University Press, 2012) 13-18.
} 
Having identified phenomena as possible solutions to problems, the analysis can be reapplied. So, in the case of law, having identified the evolution of an autonomous legal system, separate from other social systems such as the political, scientific, economic, religious, art and mass media, as a solution to the problem of how society could have reached its current level of complexity, one can consider what problems need to be solved in order for law to exist and evolve as an autonomous social system, examining various phenomena as possible solutions to these problems. Functional analysis is not therefore restricted to the most general problems of sociological inquiry. Through its re-application to the solutions identified for problems at a more general level, functional analysis can be used to consider more particular phenomena. The process of re-application allows macro and micro phenomena to be brought into a relationship with each other. In Law as a Social System Luhmann shows how the problem for law, as one of society's sub-systems, is that of autopoiesis. ${ }^{22}$ How does law continue to reproduce itself, from itself, within an environment (the rest of society) that is itself in a constant state of evolution? Law as a Social System analyses law, and sub-topics within law such as justice, legality, the courts, and legal argumentation, from this perspective. For what problem, in terms of law's ability to continue (and to continue to evolve and become ever more complex) as an autopoietic system, is legal argumentation the solution? There is no suggestion here that legal argumentation, or any of law's other structures,

\footnotetext{
${ }^{22}$ Luhmann's later sociology is referred to as autopoietic systems theory. For a succinct statement of the meaning of 'autopoiesis' see the 'Glossary of Key Terms' in Hans-Georg Moeller, Luhmann Explained: From Souls to Systems (Open Court, 2006) 215-16, and chapter 1 'What is Social Systems Theory', in which autopoiesis is described in its application to the understanding of body, mind and society, as biological, psychic and social systems. For a clear statement of law as a social autopoietic system involving 'self-observation, self-constitution, and self-reproduction', (at 33) see Gunther Teubner, Law as an Autopoietic System (Blacwell, 1993) ch 3 'Law - A Hypercycle?
} 
provides a necessary and unique solution to any of society's problems. There are always other solutions (other functional equivalents). ${ }^{23}$ Nevertheless, by approaching legal argumentation from this perspective, Luhmann is able to offer a different account of the character, forms and possibilities of legal argumentation (and in turn legal reasoning) from that offered within much mainstream jurisprudence. As a re-application of functional analysis, Luhmann links his consideration of legal argumentation to the broadest of sociological questions - what are the conditions that allow modern society to be functionally differentiated $?^{24}$

\section{What is Legal Argumentation?}

\footnotetext{
${ }^{23}$ Luhmann's functionalism engages with what he calls 'functional equivalence'. Any solution to any problem within society could have been solved differently. This applies at the level of society as a whole (problems solved by law could have been solved by other social systems) and at the level of each of society's sub-systems. But, in focussing on what problems are solved by what structures, one can identify what other solutions would need to develop, in order for any particular structure to be replaced.

${ }^{24}$ Functional differentiation is taken here to refer first to the claim that, within modern society, activities such as politics, the economy, religion, science and law are autonomous systems, and secondly to the claim that their autonomy has allowed (and stimulated) each of these systems to develop an ever increasing complexity, resulting in a society which is in turn ever more complex. For Luhmann's conclusive statement see his '4.8. Functionally Differentiated Society’ in ch 4 'Differentiation', Theory of Society Volume 2 (trans Rhodes Barrett, Stanford University Press, 2013) $87-108$.
} 
As mentioned, in his observations on legal argumentation Luhmann distinguishes his own analysis from what he refers to as 'theories of argumentation'. These are attempts to identify legal argumentation with the provision of reasons. Whilst legal argumentation involves reasons, and those who make legal arguments will present their arguments as the best reasons for a decision, Luhmann is critical of those who (he gives the particular example of Alexy's $A$ Theory of Legal Argumentation) attempt to generate theories that seek to account for legal argumentation as a process in which poor reasons are replaced by better, or best reasons, or better or best forms of reasoning. Instead, and in keeping with his version of functional method, Luhmann asks the question: what problems are solved, for the legal system, by legal argumentation? ${ }^{25}$ We need to break this question down into two: what does Luhmann identify as legal argumentation; what problems does it solve?

In his analysis of legal argumentation Luhmann distinguishes between legal decisions and legal arguments. A decision applies the legal code, changing the state of the system (LASS, 305). ${ }^{26}$ Something has been coded legal, or illegal, and this forms the basis for further applications of the code. Legal debts can form the background for enforcement procedures; unlawful debts might precipitate restitution procedures, etc. But legal argumentation does not

\footnotetext{
${ }^{25}$ Functional analysis also includes asking about the conditions that make it possible for legal argumentation to provide a solution to a problem: LASS, 315 .

${ }^{26}$ See Morten Knudsen 'Displacing the Paradox of Decision Making: The management of contingency in the modernization of a Danish county' in David Seidl and Kai Helge Becker (eds) Niklas Luhmann and Organization Studies (Liber, 2005) ch 5 for a relevant example of the paradoxes of decision-making (relevant in the sense of exploring the differences between argument and decision).
} 
do this. Instead, it prepares the system for the application of the code. Whilst there is legal argumentation, the application of the code remains undecided.

Luhmann has his own version of the easy case, where legal argumentation does not arise. The legal system operates with vast numbers of operations which are conducted on the basis that the case at hand can be dealt with through a literal reading of legal texts - especially statutes. In these cases, the application of the legal code, in advice, or decisions, operates with relative certainty without argument. The text suffices. This is not a claim that these cases operate without interpretation. Interpretation is an unavoidable element in any communication. Rather, it is an observation on vast numbers of legal operations which occur daily. In the niches of the legal system, legal advice is given, cases are decided, or people make legally sound arrangements (LASS, 306) by looking up 'the law' in texts. Luhmann is not claiming here that literal interpretation, or even plain meanings are a quality of some texts, regardless of the context in which they are read. ${ }^{27} \mathrm{He}$ is simply noting that looking up the law in texts happens in innumerable concrete situations where this suffices to know what the law requires or allows. What then triggers legal argument? Legal argument arises 'in most cases' where there is something unsatisfactory with the result produced through attempts to find a clear

\footnotetext{
${ }^{27}$ One hears echoes of significant jurisprudential debates, such as that between Fuller and Hart over the meaning of 'vehicles in the park'. Gerald Postema's account of Hart's response to, at least, 'moderate' Realism includes the possibility that he 'sought to insulate reasoning in the core from the context-and purpose-sensitive argumentation characteristic of reasoning in the penumbra ...' ('Positivism and the Separation of Realists from their Scepticism' in Peter Cane (ed) The Hart-Fuller Debate in the Twenty-First Century (Hart Publishing, 2010) ch 15, at 266). Luhmann's own reference in relation to issues concerning the relationship of interpretation and context is to Stanley Fish (LASS, 307 , fn 8).
} 
statement of the law in a text. Luhmann gives the example of literal interpretations that yield results that may not give enough weight to a party's interests, or which have consequences which the author of the text could not seriously have intended. One could add other possibilities, such as the failure to find a clear answer to an issue by looking up the law in texts (the so-called 'gap' problem). Faced with this experience, communications move to a different level. The text is no longer read as a statement of what the law requires or allows. Instead, the issue becomes 'how' should this text be read? Again, in many situations, things stop at this stage. A consideration of the purposes that can rationally be attributed to the author of the text may suffice. But argumentation goes beyond these forms of interpretation. It involves the evaluation of arguments in relation to their 'persuasive powers in the process of communication and in relation to their impact on communication'. (LASS, 307). ${ }^{28}$

The practice of legal argumentation has generated theories which attempt to explain legal decisions in terms of what constitutes good legal reasons. Whilst Luhmann does not identify all the authors of these theories about which he offers his sustained critique, ${ }^{29}$ his description of how such theories are constructed is entirely in keeping with Dworkin's account of the nature of legal argumentation in Law's Empire:

Someone who understands reasoning as a reference to reasons will feel the necessity to find reasons for the reasons as well. Someone who must find reasons for reasons needs tenable principles. Someone who refers to principles ultimately refers to acknowledged principles in the environment of the system. This is especially the case

\footnotetext{
${ }^{28}$ This quote points to the reasons why one needs to understand legal reasoning in terms of legal argumentation, rather than the other way round.

${ }^{29}$ With the particular exception of Alexy: LASS, $310 \mathrm{fn} 17$.
} 
when such principles carry the additional signature of 'moral', 'ethical', or 'reasonable' principles. If a theory of argumentation is constructed in this way it cannot accept the thesis of operative closure of the legal system and will tend to make use of reasons which arise from the practice of argumentation itself, to contradict this thesis. ${ }^{30}(L A S S, 312)$

\section{What problem is solved through legal argumentation?}

This is an appropriate moment to address legal argumentation from a functionalist perspective, and ask to what problem it provides a solution. For the legal system to develop its present level of complexity there has to be a level of consistency commensurate with the generation of extremely complex legal meanings. ${ }^{31}$ In addition, it has to evolve in response to the evolution of other systems within society. So, whilst high levels of consistency (of meaning) are needed to be achieved by the legal system for it to have its current level of

\footnotetext{
${ }^{30}$ In Dworkin's case, his iconic example from legal practice is the case of Riggs v Palmer.

31 ،... what matters is to understand how it achieves sufficient consistency in the relations of a multiplicity of decisions related to each other... The creation of sufficient redundancies is the answer to this problem.' (LASS, 318-19) A particular and, in recent times, modern version of consistency (especially significant to those concerned with theories of legal reasoning and argumentation) is that of 'coherence theory': see Amalia Amaya, 'Legal Justification by Optimal Coherence' (2011) 24 Ratio Juris 304 (and now her book The Tapestry of Reason: An Inquiry into the Nature of Coherence and its Role in Legal Argument (Hart Publishing, 2015)); however, on the difficulties of conceptualising coherence for these purposes, see Stephen Pethick, 'On the Entanglement of Coherence' (2014) 27 Ratio Juris 116 . This recent theorising is we believe equally open to Luhmann's critical observations on 'theories of legal argumentation'.
} 
complexity, this complexity could not have been reached (and will not be able to be maintained) if consistency were the legal system's only achievement. It also needs to develop mechanisms that facilitate variety, allowing outcomes (the coding of legal and illegal, and making of legal decisions) to vary in response to changes that take place in the rest of society. But the focus here is on the ability of the legal system to continue its autopoiesis, and not whether legal argumentation, or any other legal operation, is functional for society in terms of its ability to deal with general social problems. Law's need for variety in order to continue its autopoiesis addresses the needs of law, not the needs that the rest of society might have of law. Law needs to motivate human beings to seek legal operations, which will occur with decreasing frequency if it does not evolve within an evolving environment. But law can thrive in these terms without solving social problems, just as politics can generate ever more, and ever more complex, communications without solving such fundamental problems as the degradation of the planet, world poverty, etc. ${ }^{32}$

\footnotetext{
${ }^{32}$ There is a substantial body of literature which seeks to address the question of whether law, as a closed system, can address the needs of its environment including: the needs of its physical environment (for example Andreas Philippopoulos-Mihalopoulos, Niklas Luhmann: Law, Justice, Society (Routledge, 2010) especially chapter 4); the needs of other social sub-systems addressing issues such as reflexive law (for example Gunther Teubner, 'Substantive and Reflexive Elements in Modern Law' (1983) 17 Law \& Society Review 239, John Patterson, 'Reflecting on Reflexive Law' in M. King and C. Thornill (eds.) Luhmann on Law and Politics: Critical Appraisals and Applications (Hart Publishing, 2006), Richard Nobles and David Schiff, Observing Law Through Systems Theory (Hart Publishing, 2013) ch 7 'Control through Law', Ralf Rogowski, Reflexive Labour Law in the World Society (Edward Elgar, 2013)); or the needs of individual human beings (for example GuntherTeubner, 'The Anonymous Matrix: Human Rights Violations by "Private" Transnational Actors' (2006) 69 Modern Law Review 327.
} 
Consistency is only possible if some legal decisions can be identified within the system as errors: wrong decisions. Error cannot be equated with injustice alone (at least in any metasense), ${ }^{33}$ as this would not produce consistency. Nor can it be equated with a holistic sense of consistency, across the legal system as a whole, as no single operation of the legal system could accommodate an observation of the whole of the system (aside from the logical impossibility of that operation being able to observe on itself whilst purporting to observe on the whole of which it forms a part). So error, as inconsistency, has to have a local application. Every upheld appeal identifies the decision below as 'wrong', but this should not be interpreted as necessarily the same as error, for this would conflate those decisions where the legal system has identified better reasons for the new decision with cases where it regards the lower decision as having at least an inadequate, or even no justification at all. For Luhmann, these two different kinds of 'wrong' distinction have to be kept separate if one is to understand the functional role of legal argumentation. The legal system needs to be able routinely to identify errors in order to maintain sufficient levels of consistency. These must not only be something which can be identified on appeal, but identified, to a sufficient degree, in anticipation of appeal, to allow routine and sufficiently consistent decisions to be made and anticipated. In addition to this role, legal argumentation must create the conditions where the legal system can evolve itself in what it communicates to itself is progress, by the adoption of what it communicates to itself are 'better' reasons. These two functions cannot be reduced to a single distinction, as would occur if one treated all successful appeals as the

\footnotetext{
${ }^{33}$ Of course Weber was right in identifying modern law with the formally rational rather than the substantively rational, etc.
} 
correction of error. A decision without error may still be overturned in favour of better reasons. $^{34}$

Luhmann recognises the role played by appeal courts in limiting the possibilities of what can be legal by the development of doctrine. The appeal courts are institutions where legal meanings reach their greatest levels of interconnected complexity. ${ }^{35}$ Legal doctrine is generated through an endless practice of comparing applications of the code, and accounting for those applications by a process of treating like cases alike. Here the complexity of legal argumentation reaches its height. ${ }^{36}$ These are also places where the indeterminacy of all

\footnotetext{
${ }^{34}$ Identifying legal errors is an operation where, Luhmann argues, logic plays a more important role than reason. Errors are routinely identified by communications which utilise logic (particularly deductive reasoning), namely to identify whether a decision does or does not comply with a legal standard (see LASS, esp. 319 on error as obvious inconsistency, and 352 on the network of logical reasoning as part of legal argumentation). Logic also operates within legal argument by facilitating access to the legal consequences of accepting particular reasons. The relevant consequences here are not principally the statistical probabilities of different behaviour, but the implications for other legal norms and consequent changes to what is permitted or forbidden.

${ }^{35}$ For Luhmann, judicial semantics are a form of hyper-correction in the use of language which operates as a feedback loop into the circulation of legal communications, tightening what can be claimed to be legal. Luhmann places this loop at the 'centre' of the legal system, and distinguishes it from looser meanings allowed at the periphery. Similar centres operate in other systems in similar ways. So, for example, the banks occupy the centre of the economic system, given their role as institutions in establishing ever more complex conditions for what makes 'payment' possible.

${ }^{36}$ A good representation of this is the condition that allows a limited number of appeals to the highest appeal court in the UK, the Supreme Court, namely that a point of law of general public importance is involved.
} 
forms of legal argument is most apparent. The normal case on appeal involves at least an arguable case for and against the appealed question, a condition evidenced by the willingness and ability of counsel to present their arguments, or leave having been given to appeal. And whilst all judgments take the form of a presentation of what has been selected as the 'better' argument and reasons, the winning argument in any contested case is invariably open to criticism that the decision could have gone differently, based on a different assessment of the nature and strength of one or more of the elements of the judgment. So we cannot say that the presence of appeal courts, in themselves, 'solves' the legal system's need for consistency and evolution.

\section{The role of redundancy within legal argumentation}

In common with other accounts of legal reasoning, Luhmann claims that there is an 'invisible hand' which operates to allow the legal system to achieve the level of consistency and variety that it needs for its current state and further evolution. Two such accounts within legal theory are the economic analysis of law and theories which seek to describe legal decisions as a form of 'politics' (an approach common to much critical legal theory). Both of these rely on factors which are external to law when dealing with any potential indeterminacy of law, which is not to say that either is committed to a strong thesis concerning law's indeterminacy. In the case of the economic analysis of law, the claim is that any indeterminacy of legal reasoning as a basis for selecting between legal arguments can be tolerated due to the sensitivity of legal decisions to economic considerations. The future stream of costs and benefits likely to follow from alternatives operate to stabilise legal decisions, with legal doctrines constructed in order to ensure that law reduces the costs of transactions and thereby contributes to efficiency. Attributing legal decisions to politics in cases of indeterminacy can 
be external to the legal system in two different senses. First, the claim that political considerations operate to stabilise legal operations can be interpreted as a claim that the legal system is responding in a consistent manner to the communications of another system: the political system. Secondly, the claim that politics provides the necessary element of consistency and variety which legal argumentation could not provide for itself can be external in the sense that it points to something that lies outside of all systems, namely the commitments of legal actors, their unspoken and often un-self-recognised preferences for particular values and outcomes over others. ${ }^{37}$

By contrast to these external 'invisible hand' explanations, Luhmann offers an analysis that seeks to locate the 'invisible hand' basis of selection inside the legal system. This invisible hand is the system's need for redundancy. Redundancy is a concept that originates within information theory. ${ }^{38}$ A communication generates information. But it can only do so against a background of redundancy. Redundancy is the existing state of information in a system prior to a new communication. Information can only be extracted from communications by the

\footnotetext{
${ }^{37}$ One can also regard some of the developments of Hart's analysis as an external 'invisible hand' explanation for the possibilities of sufficient consistency in the legal system's decisions. The interpretation of the rule of recognition as a 'social convention' type rule of judicial behaviour (HLA Hart 'Postscript' in The Concept of Law (Clarendon Press, $2^{\text {nd }}$ edn 1994) 263-8; Andrei Marmor, 'Legal Conventionalism' in Jules Coleman (ed.) Hart's Postscript: Essays on the Postscript to the Concept of Law (Oxford University Press, 2001) ch 6) in any jurisdiction points towards unspoken understandings of what can constitute a source of law that re-enforces doctrinal statements.

${ }^{38}$ For a readable introduction to this concept within information of theory, relying in particular on the work of Claude Shannon, see James Gleick, The Information: A History, A Theory, A Flood (Fourth estate, 2011), ch 7 'Information Theory' and ch 8 'The Information Turn'.
} 
process of identifying what difference the communication makes in terms of information from what existed before. The information contained in a communication is the new or 'surprise' which it generates, by comparison with what existed before. ${ }^{39}$ The easiest way to think about this is in terms of a conversation between two parties. Each new communication occurs in the context of what has been said up to that moment. To extract information from a communication in the context of a conversation we have to see what the new communication adds. This requires us to subtract the information provided by communications up to that moment (the redundancy) from the meaning of the new communication, in order to identify the new information. If no new information is added by a fresh communication, then that communication is a repetition. ${ }^{40}$ Alongside redundancy, there is also variety. Variety is the possibilities of communication that exist within an information system prior to the next communication - the next item of information which that system can generate. These are always limited possibilities. Meaningful communication is only possible because earlier communications restrict what information can meaningfully be communicated next. But this is not a deterministic process. There is always a range of information that could be generated next in any information system. Indeed, if there were no such range, then the next communication would not generate any information that did not already exist.

Luhmann uses this distinction, between redundancy and variety, to re-state the problem which is solved, within the legal system, through legal argumentation. Information cannot be generated without redundancy, as they are reciprocals of each other. Their inter-relationship

\footnotetext{
${ }^{39}$ To put this in the terms that Luhmann regularly uses (e.g. Social Systems (trans. J.Bednarz, Jr. Stanford University Press, 1995) 75; reference at n 14, 98) by quoting Bateson: 'A difference that makes a difference'.

${ }^{40}$ Note that if the communication is identified as nonsense, that is new information.
} 
is not, however, a zero sum game, with any decrease in redundancy resulting in an increase in variety (and a corresponding increase in 'errors'). Much of information technology is devoted to removing unnecessary redundancy - prior information whose absence from the ongoing message will not affect the accuracy of the new information being generated (which is what is commonly known as 'data compressing'). ${ }^{41}$ But some level of redundancy is always necessary. In particular, and to quote Shannon, uncertainty is avoided (or in the case of information theory engineering error is reduced) by 'exploit[ing] that anyone speaking a language possesses, implicitly, an enormous knowledge of the statistics of the language.' Common prior knowledge of the range of possibilities of what can be said, written, signed or signalled next, is crucial to reducing the inconsistencies of interpretation. ${ }^{42}$ This is why, for example, timetables adopt a common grid format all around the globe, establishing a common knowledge of the range of information that can be expected within each cell within the table.

This concern with redundancy is also relevant to the legal system: what redundancies can be eliminated without increasing the inconsistencies in the interpretations given to legal texts? And in the context of law's evolution, what redundancies can be introduced which increase the variety of law's responses to its environment without at the same time increasing the

${ }^{41}$ E.g. in language - "shut the door to the barn" can be replaced in the context of persons within reach of the barn door, with "shut the door" or even "door".

${ }^{42}$ Shannon's classic statement, on which much of the development of information theory is based is: 'The general rule is simple: every time the number of alternatives is increased by a factor of two, one bit of information is added.' Gleick, n 38 above, at 261. Because information takes the form of reducing uncertainty, it depends on the existence of prior probabilities. So, if there are two possibilities prior to the new information, that information will constitute a 'bit'. 
inconsistencies of the interpretations given to legal texts? From a functional perspective, these are problems to be overcome. Can law respond to changes in its environment without losing its consistency, which is linked in turn to its general social function of generating normative expectations that are appropriate (sufficiently technical) for a complex society? Law cannot continue to execute its social function simply by abandoning the redundancies which it has built up through legal argument as would occur, for example, if judicial decisions were reached on an ad hoc basis, in response to what the decision maker saw as justice, or efficiency. Whatever the possibilities for this form of decision making in smallscale pre-modern communities, it would not sustain the complex normative expectations required today. Instead, law can only evolve in a manner appropriate to its current levels of complexity by developing new forms of redundancy that can stabilise and thus allow for the possibility of new varieties.

This is a problem which legal argumentation, up to the present, has solved for the legal system. Whilst new legislation is a major source of increased variety within modern national legal orders, it is not primarily where the legal system identifies errors, or seeks to ensure consistency in the meaning attributed to legal texts. ${ }^{43}$ If the legal system is to exhibit increased and different forms of variety, without losing consistency (precision) then it has to maintain 'sufficient redundancies'. This is not achieved via most legislation, or by the decisions of courts delivered without reasons. It has been achieved (and if the legal system is to continue its social function it must continue to be achieved - or the problems solved in some other way) by the legal argumentation that accompanies legal decisions when the

\footnotetext{
${ }^{43}$ Despite the highly developed practices of drafting legislation. However, there may be some forms of legislation that attempt to play this role, for example consolidating statutes.
} 
interpretation of legal texts is contested. This is possible because legal argumentation reutilises and re-affirms the system's redundancies and, in the case of structural change, requires new redundancies to be established. ${ }^{44}$

\section{Understanding redundancy}

In order to understand how redundancies might ground legal arguments we need to situate legal argumentation within the operations where it occurs. Prior to any matter being the subject of an appeal court hearing, it must have already been the subject of a first instance decision. Therefore, it must have passed through an originating instrument (writ or summons in the Anglo-American system), pleadings, discovery and inspection (if documentary evidence is relied upon) and oral examination (if witnesses have given testimony). There will have been a judgment with reasons, and an application to appeal, possibly involving leave. Reaching this point utilises significant elements of redundancy. If we start by considering the kinds of structures that legal positivists might rely on in their accounts of what stabilises the identity of the legal, the authority of statutes and the hierarchical authority of courts' decisions, one cannot easily introduce arguments that offer a headlong challenge to such ideas of authority. The authority of statutes and courts' decisions will have formed part of the communications which have led by stages to the present context, as well as the jurisdiction and authority of the judge or judges who will be called upon to decide the matter being appealed. The citation of particular statutes and appeal court precedents (variety) depends on

\footnotetext{
44 ،... redundancy is not the only condition on which the autopoiesis of the system depends. A second condition is variety, and by that is meant the number and diversity of the operations which a system can identify as its own and which it can execute.' (LASS, 320)
} 
the common redundancy of their status as authorities. ${ }^{45}$ This is what Luhmann means when he says that: "From the viewpoint of coordination, redundancy is the "invisible hand" of the system. However, the visible hand, that is, the hierarchical line of command, would not be an example of the contrary case as the metaphor may suggest. It is a case of its application.' (LASS, 318)

This invisible hand is not being applied because of the internal commitments of lawyers, or because of the external need of the legal system for something called 'legitimacy', but the need to make precise legal communications and the constant repetition of the redundancies which make such communications possible. For Luhmann, legal concepts are developed via a process of repetition, and condensing. Martin Shapiro, in his article 'Toward a theory of Stare Decisis, ${ }^{46}$ (a work cited by Luhmann) provides an explanation of how this occurs. Shapiro distinguishes between the different functions which redundancy executes within information systems. First, at the syntactic level, redundancy is simply the background condition for the generation of information. Whatever, within a system, is redundancy, is not information, and vice versa. At this level, redundancy cannot have any information value. Information has to be linked to contingency and surprise. If what had already been said about a subject told us everything that could be said further, then further communications would have no information value. To put this observation another way, further communications would simply repeat the information that had already been provided which, at the syntactic level,

\footnotetext{
${ }^{45}$ This statement of the context of appeal cases could be repeated for any operation of the legal system. Any operation occurs against a background of prior operations, which will have utilised many of these same forms of redundancy. So, for example, issuing a writ will involve resort to court rules, which will themselves be linked to earlier appeal decisions and statutes or statutory instruments. ${ }^{46}$ (1972) 1 Journal of Legal Studies 125
} 
means that they generate no information. But at the semantic level (which deals with meaning) and the pragmatic level (which deals with human behaviour) redundancy has additional functions. At the semantic level, the repetition of information, which is redundancy at a syntactic level, provides information about the status of that redundancy for the sender. The implicit message, in any use of redundancy, is that the sender accepts the information that has already been transmitted within that redundancy. A repetition of that redundancy, by that sender, provides further reassurance that the sender accepts the information contained. And a repetition of that redundancy, from multiple sources, contains reassurance that there is a widespread common acceptance of that redundancy - that it is something that the receiver can rely upon when generating further communications. Thus, at the pragmatic level (which deals with the effects of information on human behaviour) redundancy encourages reliance. Applying this analysis to the legal system allows Shapiro to account for the repetition of leading authorities, and the constant re-use of legal concepts. These are not only the common basis for the generation of new information, but also, in their use and re-use, a common assurance to users that they have an accepted status within the legal system. It is this repetition of information (the redundancies), rather than the internal beliefs of lawyers, or any survey of their opinions, which creates the experience of 'propositions of law generally treated as true in contemporary legal practice'. (Dworkin n 11 above, 14)

Note that, in keeping with Dworkin's ideas that no part of law is free from the process of interpretation, and that law is an interpretative concept, this is not a claim that concepts or formal sources of law cannot themselves become the subjects of legal argument. It is simply that those arguments have to be generated by legal redundancy, and thus cannot deconstruct the communications on which they rely. This is a condition both for legal argumentation, and for the reasons given in the decisions which follow legal arguments. It is also a basis for 
identifying legal errors such as, for example, failing to take account of a statutory provision. The routine creation of legal arguments by reference to statutes, constructed on the basis that statutes normally have equal authority (that their authority is not content dependent) does not normally ${ }^{47}$ allow a legal argument that a statute which has relevance can nevertheless be discounted.

A comparison between Luhmann and Hart may further assist our understanding of Luhmann's account of the role played by redundancy. Luhmann, like Hart, acknowledges the importance of formal sources of law (texts) for the stabilisation of the interpretation of law. But unlike Hart, he does not see this as the result of the application of rules, via logical analysis or hermeneutic predisposition, from a foundational commonly accepted master rule or rules. Luhmann's theory of systems does not acknowledge that anything is foundational. A system may describe some of its redundancies as essential, where these are routinely relied on to generate further information, but this does not mean that these redundancies are themselves immune from further development. Take a specific example: the role played, within the UK legal order, by the doctrine of parliamentary sovereignty. This doctrine would, for those reading Hart prior to 1972, have been accepted as an ultimate rule or justification for an ultimate rule about the authority of statutes, namely a part of any rule of recognition. In terms of Luhmann's analysis, its role as an ultimate rule is a self-observation, by the legal system, at its centre (the courts) on the role played by this doctrine in so many legal operations: it forms a link in the communicative processes which brings many issues to be decided by a court. But this doctrine is not immune to re-interpretation, if the conditions of redundancy alter. This was shown in the House of Lords decision in ex p Factortame (no 2). To find that parliamentary sovereignty had remained unchanged since 1972 (the date of the

\footnotetext{
${ }^{47}$ Only normally - see the discussion of ex p Factortame (no 2) [1992] 1 AC 603 in the text below.
} 
European Communities Act), with the result that Community Law could not be relied upon where it conflicted with a statute passed since 1972, would have caused a significant loss of redundancy, for Community Law had become a major basis for legal decisions between 1972 and 1988 (the date of the relevant statute in this case, the Merchant Shipping Act). On the other hand, abandoning the rule that later statutes which conflict with earlier statutes take precedence would also have represented a significant loss of redundancy for the UK legal order. The result was a typical development of legal doctrine - the creation of an exception, which thereby minimised the loss of redundancy. The 1972 Act was interpreted as a delegation of authority by the UK Parliament to create law at the community level which was to take precedence (until the 1972 Act was repealed by an express statute to that effect) over subsequent statutes which had conflicting provisions. For other UK provisions (subject of course to the possibilities arising in further disputes and legal arguments) later statutes would continue to repeal earlier ones in the event of conflict, on the basis that these statutes continued to have equal authority. Applying Hart's analysis, this decision is explained by a change in judicial commitment and practice as to what constituted the parts of the ultimate rule (rule of recognition) in the UK legal order. Focussing instead on redundancy, one can see that what had altered was not the internal motivations of the British judiciary (who had become more EU favourable and less nationalistic), but the configuration of legal communications within the UK legal order - so many legal decisions were by then justified in terms of Community Law. In finding that the 1972 Act represented a temporary delegation of sovereignty to Europe, the House of Lords reached a decision which preserved both sources of redundancy - community legislation and European Court decisions, and the status of statutes of the UK Parliament. 
This need for redundancy as a background for information is not limited to the acknowledgement of a hierarchy of authorities. Even if the status of these authorities are, ordinarily, beyond challenge ('propositions generally treated as true in contemporary legal practice'), this would not provide sufficient redundancy for meaningful legal argumentation. All interpretation has to occur 'in context' and, in the case of legal argumentation this has to be a legal context. ${ }^{48}$ For lawyers to argue about the law there has to be common ground as to where, within the law, the dispute is located. (There has to be common ground as to what propositions 'surround' the one(s) in the dispute). The legal system has had to generate redundancies that not only identify itself to itself ('this is the law') but identify where, within itself, the relevant dispute arises ('this is a case of ...' $)^{49}$ This has required the creation of subfields of law and, as part of this, concepts. From this perspective, and using a spatial metaphor, concepts such as tort, property, contract, trust, constitutional, criminal, civil, etc. represent important aspects of the internal geography of law, as do the concepts that each

48 ،...argumentative orientation is constantly shifting because its recursive support shifts from situation to situation.' (LASS, 314)

49 "The crucial point is that the system can "recall" internal contexts from the past and through that reduce the scope of possible operations in the present.' (LASS, 306) These contexts are formed out of texts: statutes, decisions, constitutions, and commentaries. 'In the normal process of decision-making, the system does not observe itself as a system (in an environment) but as an accumulation of legal texts that refer to each other.' (LASS, 305) Neil MacCormick ('Law as Institutional Fact' (1974) 90 Law Quarterly Review 102 at 105) clarifies the role of concepts in law thus: 'Concepts ... are essential to the enterprise of analysing legal systems into coherent sets of interrelated rules.' Luhmann (LASS, 340) expresses this succinctly: 'Concepts enable choice of access to already proven distinctions without having to go back to the sequence of their generation, and they also organize new emergent distinctions on that level.' 
generate at more specific levels. ${ }^{50}$ As such, these concepts do not require an overall and constant consensus as to what constitutes their point, purpose, or justification. They are all open to possible disagreements with respect to these. Legal academics may engage in critique which challenges the rationale given for any concept, by pointing to cases where the features claimed to have been essential to a concept have been absent, or offering a different justification for the cases which are typically cited in support of such a concept. ${ }^{51}$ And, as in our example of ex $p$ Factortame, in the right circumstances, the legal system can itself generate the conditions where even the most generally re-used concept is subject to reexamination. ${ }^{52}$ But the possibility of such critique, and the absence of total consistency in the

\footnotetext{
${ }^{50}$ A system seeks to identify systematic relationships within itself to a far greater extent than it does with its environment. So, for example, the manner in which contract operates as a internal 'context' is far more systematic within law than the manner in which the economy works as a 'context' for contracts. Law's redundancies are located within the re-iteration of its internal contexts to a far greater extent than its internally constructed external contexts.

${ }^{51}$ See Charles Fried 'The Artificial Reason of the Law, or: What Lawyers Know' (1981) 60 Texas Law Review 35, another citation used by Luhmann. Fried shows how economic analysis can operate to dissolve the differences between concepts like contract, tort or unjust enrichment which, in practice, nevertheless maintain their insolubility or 'lumpiness'. Moral philosophy can offer some explanation for their separation but only at a level of generality, while it offers no explanation for the specifics of these concepts in particular jurisdictions.

${ }^{52}$ Within systems theory such moments would be seen as the unfolding of a paradox. The paradox is the lack of any foundation for law, which would be revealed if the reaction of the system to an interrogation of its redundancies was an admission that there was no foundation to the distinction between what is legal or illegal. Rather than being paralysed by such questions, legal argument, developed using surrounding redundancies, leads to the further evolution of the law - 'a step away from the unutterable' (Philippopoulos-Mihalopoulos, n 32 above, 65).
} 
application of concepts, does not cause these concepts to be removed from the system if they still operate to offer redundancy, i.e. to provide a stable basis for making communications, including arguments, which parties are motivated to produce. ${ }^{53}$

In his discussion of concepts of law in Law as a Social System, Luhmann notes a tendency for the pursuit of consistency to have reached levels in the past, which have created a tension with the second functional need - for evolution, or in information theory terms - for variety, which can then be selected by the system as redundancy for the production of new forms of variety. Consistency in the elaboration of concepts can threaten the system's capacity to respond to developments in the rest of society. It is not enough for the legal system to elaborate itself to itself through the attempt to develop consistent concepts, it has also constantly to apply those concepts to its own version of its (external) environment. ${ }^{54}$ The

${ }^{53}$ See, for example, Simon Deakin's discussion of the ongoing role played in employment law by concepts developed within the law of master and servant. 'Evolution for our time: A theory of Legal Memetics' (2002) 55 Current Legal Problems 1. The need for motivation was explained by Luhmann as 'invocation sovereignty', see 'The Autonomy of the Legal System' in The Differentiation of Society (trans S. Holmes and S. Larmore, Columbia University Press, 1982) 124.

${ }^{54}$ This can lead to the evolution of sub-fields, as with the development of the contract of employment as part of labour law. In such developments, the legal concept, and the recognition of a particular aspect of law's environment, develop together: "Crucial in his analysis is the creation of "sub models" within the legal system with which law observes changes in its environments and then uses them as “means of self-modelling."' Rogowski, note 32 above, 39, relying on Marc Amstutz's writings on the evolution of commercial law. The ability to do this depends on loose coupling between such subfields and the law applied to the more general environment from which the sub-field is distinguished. This co-evolution also involves what Luhmann referred to as structural coupling: where one system 'presupposes certain features of its environment on an ongoing basis and relies upon them 
environment (not just the physical one, but also the social one, namely other social systems) is not immediately available to any system. Like other systems, the legal system can only observe on the rest of society via its own operations. This means that social conflicts, and the interests which underlie those conflicts, cannot be the subject of judgement, or 'balance' in themselves. They can only be observed upon within the legal system as a process of comparison, within legal procedures, of what the legal system identifies as itself, and what it identifies as its environment. ${ }^{55}$ To make any proposition that takes the form "the application of the law, to facts $X$, requires $Y$ " there is a need to identify the law separately from the facts to which it is to be applied. Luhmann discusses this need in terms of a move from a $19^{\text {th }}$ structurally' (LASS, 382). In the case of contract, one has a legal concept that couples, via individuals' expectations of expectations, with communicative events arising within the economy. Law can then evolve a sub-field, such as labour law, by articulating both evolution of its own concepts (with the contract of employment combining both contracts and the law of master and servant) and at the same time identifying this conceptual evolution with a distinction within its own environment (the field of industrial relations).

${ }^{55}$ The discussion, within systems theory, of whether law can address the needs of other social systems focusses on whether law can become aware of itself as a system within an environment of systems. 'The theory of reflexive law argues that the legal system becomes consciously reflexive when it recognises that the societal domains which it purports to regulate, and to which it also seeks to respond, are themselves independent autopoietic systems.' (Rogowski, n 32 above, 33) For a discussion of the ability of law to achieve this in the area of human rights, see Katauyoun Baghai, Social Systems Theory and Judicial Review: Taking Jurisprudence Seriously (Ashgate, 2015) and our review article to be published in 2016 in International Journal of Law in Context. The additional problems preventing law, as a social system, from recognising the needs of the physical environment (which does not communicate) are discussed in Philipopoulos-Mihalopoulos, $\mathrm{n} 32$, especially chapter 4. 
century 'jurisprudence of concepts' to a $20^{\text {th }}$ century 'jurisprudence of interests' (LASS, 343351). Luhmann's point here is that both concepts and interests are required for the execution of legal argumentation, and that both are internal constructs of the legal system. If conceptual reasoning is extended via generalised concepts with the result that it produces unacceptable (a standard discussed below) results, then the legal system responds by altering its concepts. The radical changes in society which have occurred over the last two centuries have in turn produced a lessening in the reliance of the legal system on very general concepts. This, according to Luhmann, has resulted in an exaggerated and inaccurate view of the manner and extent to which the legal system can recognise and adjudicate upon social interests, with at least some adjudication taking the form of a 'balancing' of conflicting interests. But the law cannot simply balance social interests. First, because, if it were to 'balance' interests, it could only do so in respect of interests which it both recognises and accords a positive value ('legally protected interests'); and secondly, because it could not achieve sufficient consistency (redundancy) if the comparison was simply conducted as a weighing of interests. This would represent a judgement based on the internal commitments of the individual making the assessment. The legal system needs an internal side to this comparison in order to stabilise it - which is the role played by legal concepts. It is this internal/external comparison, of concepts against interests, which gives the legal system the possibility of achieving both consistency and evolution, with a sufficiency of both redundancy and variety. ${ }^{56}$

\footnotetext{
${ }^{56}$ Brian Simpson's classic essay ('The Common Law and Legal Theory' in William Twining (ed.) Legal Theory and Common Law (Blackwell, 1986) ch.2) on the common law, representing it as 'more like a muddle than a system' reflects an estimation that gives more weight to pragmatism than concepts. Whether this is an exaggeration can be considered by contrasting Dworkin's discussion of pragmatists and conventionalists in Law's Empire. Of course, his preference is for a conception of
} 
Luhmann's observations on the move from a jurisprudence of concepts to one of interests can be linked to his observations on the functional need to create concepts which have a local effect. For a system to increase in complexity, the parts of that system need what, within systems theory, is called loose coupling. ${ }^{57}$ Strict coupling would involve a relationship in which changes in one part of the system inevitably cause changes in the other. Loose coupling is the converse, a situation in which changes in one part of the system often have no effect on other parts. This looser relationship allows for the introduction of more variety into the system, without the loss of redundancy (disturbance of currently utilised information/meaning). To put this at its most extreme: if every decision in the legal system (or even every decision by the highest appeal court in a particular jurisdiction) had implications for every doctrine hitherto developed (as would occur if every decision involved argumentation in the form of holistic reasoning, along the lines of Dworkin's Hercules in Taking Right Seriously) ${ }^{58}$ then that system would have great difficulty in developing an appropriate level of variety commensurate with the necessary level of redundancy. By contrast, if one part of the legal system is only loosely coupled with another, then changes in one part can leave all or most of the rest of the system unaffected. Law's complexity can be

\footnotetext{
'law as integrity'. A similar preference is reflected in the notion of sufficiency adopted by Luhmann, and illustrated here, but not in a Dworkinian form.

${ }^{57}$ Complex systems have to create '... a local reference that makes priorities possible without being dependent on references to the unity or totality of the system.' (LASS, 317; see also 321)

${ }^{58}$ And even, to some extent in Law's Empire, where in the final chapter 'Law Beyond Law' Hercules makes an inventive reappearance.
} 
constantly increased, in response to its environment, by the creation of sub-fields, and the introduction of concepts of more limited application. ${ }^{59}$

Legal concepts therefore operate both to connect, and to separate legal communications. Bundling together connections under the heading of tort, trust, etc, operates to insulate the redundancy of these connections from changes in other legal fields. Within legal fields, these concepts serve not only to make connections, but to do so in a manner that reduces the time taken to communicate about legal relationships. As MacCormick, in an article cited by Luhmann observed, legal concepts can logically be replaced by fuller statements of the rules which they bring into a relationship with each other. But this would involve a vastly more complicated set of communications, which would take more time to process, with increased opportunities for error. ${ }^{60}$

Legal concepts produce an internal (and manageable) version of legal consequences. If legal decisions were to be justified solely by reference to their casual effects within society, then this would in many, or most cases, deteriorate into the individual decision makers' own speculations as to what would follow. The legal system has limited ability to introduce sociological/scientific evidence of the likely consequences of its own decisions prior to reaching them, and prediction, at the level of developments within society, is hardly amenable to hard science. But assessing internal legal consequences through conceptual reasoning is possible to a far greater extent. So for example, deciding whether a change in a

\footnotetext{
59 'Only in a few respects should decisions in one sub-complex affect another ...' (LASS, 321)

60 ،...even if the theoretical objection that ... the law could be stated without the use of [concepts] is true... the very complexity of the subject-matter suggests a compelling practical justification for the continued use of such terminology.' (MacCormick, n 49 above, 113-14)
} 
rule relating to the contract of employment will increase efficiency, or profitability, or produce fuller employment is unlikely to be anything other than an exercise of subjective imagination. But understanding the linkages represented by the concept of a contract of employment, allows those making legal arguments, and those assessing them, to form an opinion of the consequences of changing the same rule on legal obligations arising under contracts of employment. This kind of consequence can be known with greater predictability, and without the same need for outside expertise. These consequences still have to be assessed in terms of their reasonableness and rationality, but again, conceptual reasoning structures what needs to be brought into comparison: opposing combinations of rights and duties. This form of consequentialism also feeds into the evolutionary process, by making legal argumentation responsible for formulating what the state of the law will be if a decision is made in favour of one party rather than another. A decision supported for reasons that will require large numbers of legal questions to be re-litigated (representing a significant loss of redundancy) has, other things being equal, less persuasive force than one that does not.

This is a good point at which to summarise the functions of redundancy. The first function is to reduce inconsistency in the meanings attributed to communications in the legal system, by creating the conditions in which it is possible, at a high level, to identify errors. A system can only generate complex meanings by restricting the possibilities of variations in interpretation, which means that it too needs to be able to use redundancies in order to be able to identify, interpretations that it regards as 'obviously inconsistent. ${ }^{61}$ However, the legal system has not evolved solely by increasing the redundancies which allow it to identify inconsistencies as 'errors'; nor by abandoning redundancies in favour of increased variety by, for example,

\footnotetext{
${ }^{61}$ Prior to such secondary observation, Luhmann defines errors as 'obvious inconsistencies' when linked to a 'systemic concept of justice' (LASS, 319) as a first order observation.
} 
making more of its decisions dependent on interest balancing or other such 'ad hoc' forms of reasoning. Rather, evolution has resulted from increases in both redundancy and variety. Instead of responding to social change by abandoning redundancies, the legal system responds by developing new redundancies, which allows for more complex forms of information to be generated. ${ }^{62}$ Instead of simply abandoning redundancies, the legal system, through the process of legal argumentation, further develops its own concepts, rules and principles. $^{63}$

Luhmann's explanation of legal argumentation by reference to the distinction between redundancy and variety can be contrasted with theories, like Dworkin's, which attempt to explain this operation on the basis of the work done within the legal system by reason. Explaining law's evolution on the basis that better reasons have replaced inferior ones, leads

${ }^{62}$ This focus is crucial to the analysis offered in this article about the function of legal argumentation. It is well represented in the following statement by Luhmann linking the problem of order within modern society and its sub-systems to the need to structure solutions: 'Solving this problem requires a continuous organization of selective processes. Meaning, then, can be conceived as representation of complexity on the higher levels of evolution, as an evolutionary universal. Systems like persons and social systems which rely on meaning for coping with complexity become by this very fact hypercomplex systems because they introduce into complex systems a representation of their own complexity.' ('Insistence on Systems Theory: Perspectives from Germany-An Essay’ (1983) 61 Social Forces 987, at 994)

${ }^{63}$ And thus some new redundancies, which can both increase variety and decrease errors. The development of legal concepts, discussed above, is an example of this. As an illustration, consider Luhmann's discussion of the concept of a legal company as a sequential conditioning programme, which is also a sequential set of heterarchical relationships (LASS, 321). If one accepts that there is a company, the conditions for its formation can be ignored, as can the conditions of its termination. 
one to question law's closure. The ranking of reasons invites consideration of external standards, such as morality. But legal argumentation can only occur on the basis of law's redundancy. This makes legal argumentation another example of the aphorism that frustrates so many of Luhmann's critics - that a system's closure is the basis of its openness. ${ }^{64}$ To make a legal argument, one needs to re-iterate law's redundancies and yet, at the same time, fail to close off all possibilities of argument. In more colloquial terms one has to find a legal 'point' which can be the subject of argument. But in making that point, one is forced to draw upon, and re-iterate, and thus re-affirm, the redundancy of all the communications that are needed to reach (i.e. to make a cogent argument in favour of) the point that is to be disputed. And, since argumentation requires two arguments, the opposing argument must similarly reach the same point of argument, and affirm the redundancies that allow this point to be reached. And this must occur, regardless of the possibility that, in different disputes, all or any of the redundancies needed to reach this point might themselves become the point of a legal argument: ${ }^{65}$ 'Then one can continue to say that the limitation of the scope of possible combinations ... is the condition for the possibility of reasons ..., and consequently that redundancy is the condition for the possibility of legal argumentation.' (LASS, 318)

Redundancy establishes the background for the identification of errors, and it operates constantly to limit what can form the basis of legal argumentation, but what, within the legal system, can disturb existing redundancies, and thus allow the system to evolve? The legal

\footnotetext{
${ }^{64}$ 'Redundancies, therefore, not only exclude information but also produce it by indicating the sensitivity of the system.' (LASS, 317)

${ }^{65}$ As Luhmann himself admits, much of this analysis of legal argumentation in terms of the limitations imposed by the need to re-use redundancies has been identified by others before him. As well as Shapiro, Luhmann also particularly recognised the work of MacComick and Levi.
} 
system, in the judgments of appeal courts, presents such changes in terms of 'better reasons' which, if taken at face value, would support Dworkin's account of what makes law possible, including Dworkin's claim that moral arguments operate within the legal system. The search for 'better reasons' not only opens the door to a search for 'best' reasons, but it also provides no clear explanation for why any individual actor should not, relying on their own judgement, seek to dispense with an established legal concept, rule or precedent when there are apparently 'better reasons' for the alternative. The need for redundancy within legal argumentation closes down the possibilities for 'better' reasons to operate, constraining the choices of those seeking to make legal arguments. Distinctions and exceptions are normally preferable to overruling, as they leave the meanings created by existing redundancies less disturbed. ${ }^{66}$ (A feature which leaves the law, regardless of the ever increasing pace of legal change, forever open to the external observation that the legal system, and the humans who occupy judicial positions within it, are 'naturally' conservative).

Luhmann attributes the generation of variety within the system to the same processes that establish law's ever increasing redundancies: the requirement 'to treat like cases alike'. ${ }^{67}$

\footnotetext{
${ }^{66}$ Speaking of established legal reasons, Luhmann says: 'Tradition makes it only too apparent how much would have to be decided differently without it. Hence new points of view are added only as exceptions to rules, which continue to be valid, or as new principles in cases which have not yet been registered or registered wrongly.' (LASS, 328)

${ }^{67}$ The need to treat like cases alike is older than any formal system of precedent, and formal precedent does not replace the need to treat like cases alike. It only alters what needs to be treated alike. A hierarchical system of courts, with reported decisions, provides a different calculus. So, for example, Court of Appeal decisions have equal authority, regardless of the judges who sit on particular occasions, whereas prior forms of precedent lacked this formality. And, the redundancies of legal
} 
This, like law's code is, at a formal level, a distinction devoid of content. Content arises from the operations which take this form. Decisions by themselves do not generate adequate levels of redundancy, as this requires individual decisions to be brought into relationship with each other. Nor do decisions which can be justified on the basis of vague standards such as their appropriateness in all the circumstances. But as Luhmann stresses, in his own account of law's evolution through history, the move away from the justification of decisions using ad hoc arguments, towards accounting for decisions on the basis of identifying reasons why one or other side of the legal code has been applied, provides the basis for law to both stabilise the application of its code and to change how it will be applied in future. ${ }^{68}$ The linking of reasons for decisions, by drawing further distinctions, allows for law to develop a technical complexity, without coding becoming arbitrary. Decisions for which no non-arbitrary grounds could (or have) been given may nevertheless be identified within the system as a straightforward legal error - a failure to apply settled law. This process of comparing cases and offering principled reasons (reasons that are capable of being re-used in future cases) is what the law principally understands within its operations as justice. This endless process of

arguments at earlier stages were maintained within legal pleadings, rather than decisions (see LASS, 329, fn 83). For a much fuller, indeed comprehensive account, see Neil Duxbury, The Nature and Authority of Precedent (Cambridge University Press, 2008).

68 'In sum, if ad hoc and ad hominem arguments are not permitted, a demand for justification arises which has to be satisfied in a different way, and that means that it must move, above all, in the direction of the identification of binding norms and the development of concepts and rules for decision-making which can be assumed to apply to other cases as well. Not until this practice is established can a concept of justice be accepted which stipulates that equal cases are treated equally, and that unequal cases are treated unequally. This leaves it up to the legal system to establish what, based on what rules, can be seen as equal or unequal.' (LASS, 248-9) 
comparison generates redundancy, but also opens new possibilities - new variety. So for example, every judgment that decides a legal issue also provides a new basis upon which new issues can be litigated (as reflected in case commentaries that identify all the new possibilities for litigation which have been brought into existence by a new authority). ${ }^{69}$ This process can also create the conditions within which some redundancies are replaced with others. As well as drawing new distinctions (creating exceptions) situations arise in which earlier redundancies no longer provide an acceptable grounding for decisions. In this situation overruling, or its equivalent (a major re-interpretation of an area of previously settled law), can occur. In keeping with the need for redundancy, such occasions are exceptional. They cannot occur whenever there are 'better reasons' for a decision, for the possibility of finding better reasons for a decision is not exceptional, but normal. As pointed out earlier, every legal argument will be linked to reasons for decisions that could have been better. As such, there is no way of constructing a legal argument for a change in the law that does not involve deference to prior decisions and the reasons given for them. The sense of what is exceptional can only be established against this background of what is normal. There is no formula which can establish the exceptionality of situations which overcomes the deference involved in legal argumentation. Sometimes this may be the result of changes in what law observes as its environment, leading to a decreasing applicability of earlier reasons. Sometimes the law to be radically re-interpreted or overruled has lost its previous levels of redundancy, as occurs in situations where exceptions to rules have eroded the ability to make decisions in accordance with the original rule with any coherent justification. The important element here is the need

\footnotetext{
${ }^{69}$ The endless openings represented by any closure through decision justifies PhilippoulosMihalopoulos' description of the construction of legal programmes to stabilise the application of the legal code, legal/illegal, also 'as enablers of uncertainty that destabilise the rigidity of the code, introducing both delay and doubt in the attribution.' (n 32 above, 74, emphasis in original)
} 
for exceptionality before abandoning existing redundancies, to allow evolution to co-exist alongside consistency, not the particular configuration of circumstances that generate the sense of the exceptional.

\section{What difference does Luhmann's sociology make?}

Luhmann's account of legal argumentation is not a predictive guide as to when legal arguments will succeed. But neither are the 'theories of argumentation' from which he distinguishes his own approach. If we take the example of Dworkin, who insists that legal argumentation seeks to present legal propositions in their best light, this formula does not tell us what, in any particular case, will be selected as the 'best'. In particular, Dworkin cannot tell us how the trade-off between 'fit' and 'value' is to be undertaken in any particular judgment (or, as discussed earlier, which propositions need to be subjected to this calculus in any particular dispute). Luhmann's description of the form in which legal arguments are generated within the legal system does not fundamentally differ from Dworkin's account. An argument which had no support from existing legal sources would not, however attractive, constitute a good legal argument. ${ }^{70}$ An argument does not occur in a vacuum, but only within a line of argument, linking the case at hand to legal propositions and to implications for the environment. But this level of description remains, for Luhmann, internal to the legal system. 'Theories of argumentation' are describing legal argumentation in the manner in which it is described within the legal system, but seeking to do so in a way that is sufficiently general to transcend particular cases. Luhmann offers his analysis of legal argumentation at a different

\footnotetext{
70 'Only if consistency with valid law is proven does it matter how good the good reasons are.' (LASS,
} 330) 
level, ${ }^{71}$ one which he calls tertiary observation. ${ }^{72}$ (LASS, 330) This indicates a distance from the internal presentation of legal argumentation within the legal system. For the legal system to achieve its current level of complexity, both redundancy and variety have needed to increase. Legal argumentation, and in turn 'theories of argumentation', present the selection of variety over redundancy (only achievable by the re-use of redundancy) as the choice of 'better reasons'. This produces a self-description in which the legal system understands itself to be constantly improving itself through legal argumentation - becoming more just, reasonable or rational - which feeds in turn into those 'theories of argumentation'. By moving to the tertiary level, Luhmann asks what the legal system achieves through this form of legal argumentation. The answer at this level is not justice, reasonableness or increased rationality, but levels of redundancy and variety sufficient for its existence and evolution.

The legal system cannot continue to evolve (continue its autopoietic existence at its current, or higher levels of complexity) unless the need for adequate levels of redundancy and variety are addressed. This is not a claim that every decision reached in response to legal

\footnotetext{
${ }^{71}$ Thus going beyond a re-description of how legal argumentation presents itself in the legal system as the provision of better reasons (than the alternative) for a decision, to consider what problem is being solved, and what conditions make it possible to solve this problem: 'This is the point at which we definitely part company with theories that relate the concept of argumentation exclusively to the criteria of reasons, for instance the reasonableness of reasons. In their place, we look for the function of the system because we do not want to subject our analysis to the reasons that are mobilized in the system itself.' (LASS, 315 fn 37)

${ }^{72}$ Distinguishing it from both primary observation, which covers any assertion that something is legal or illegal, and secondary observation, which is where the legal system communicates about earlier or hypothetical future applications of its code, as occurs in appeal court judgments.
} 
argumentation needs to achieve a particular balance of redundancy and variety. There is no 'fit' which is appropriate to every legal dispute. The functional requirement is one that is executed by legal argumentation, as a process within the legal system. Each example of legal argumentation can lead to outcomes which offer different possibilities of variety in terms of what can in future form the basis for legal propositions - radical, marginal, conservative, or none. The need for an adequate balance is one that must be executed by legal argumentation as a whole, and continuously. The task here is to see how this balance is achieved.

The distinction between redundancy and variety is not a structure (a redundancy) within the legal system and, as a semantic distinction, will rarely if ever occur within legal communication. ${ }^{73}$ So the functional requirement to bring them into balance has to be executed by communications and operations that make no direct reference to them. Redundancy is involved whenever legal propositions link to other 'legal' propositions. This occurs largely without the need for communications which recognise, or purport to negotiate, acceptable levels of redundancy. ${ }^{74}$ As Dworkin rightly observes, legal argumentation takes place against the background of legal propositions accepted as true - i.e. legal propositions which are the foundation for the argument taking place. Neither the possibilities of their replacement, nor their function in maintaining stable legal meanings will form part of the legal argument in the case at hand. There are legal communications that seem to be

\footnotetext{
73 'The concepts of redundancy and variety fall outside the framework of legal argumentation.' (LASS, 322, our emphasis) This does not mean that the distinction will never occur within law. One can hypothesize its occurrence within a dispute involving information technology, or even a copyright dispute following the plagiarism of this article!

74 'Thus, one must distinguish between the intended selection and the unintended reproduction of the redundancies of the system in each of its operations.' (LASS, 318)
} 
acknowledging the need for redundancy: the need for consistency, to treat like cases alike, and the presentation of losses of predictability which may follow from the adoption of particular legal arguments. But these arguments are not reasons why the legal system maintains an acceptable level of redundancy. To make this claim would repeat the mistake of those who seek to explain legal argumentation in terms of 'theories of argumentation' - to select particular forms of argument and claim that these arguments 'steer' the legal system. Redundancy is present (and needs to be present) even when the need for it is not recognised. It is re-affirmed in every legal argument that seeks to change the state of the legal system, since these arguments can only be made on the basis that most of the legal system stays the same. ${ }^{75}$ Indeed, not only must any argument for change be located within legal operations which re-affirm the system's redundancies (as argued above), they must also be presented in a form that diminishes the potential for extremes of variety. Legal argumentation takes the form of claims as to what the law 'is', rather than an appeal for a judge to undertake a naked act of legislation. ${ }^{76}$ To commence a legal argument in the form "what I seek is contrary to the current law" is to fail to make a legal argument. But, just as redundancy is affirmed whenever legal arguments seek change, so too variety is present whenever one finds legal arguments that appeal directly for the status quo. Any argument that claims that change would be unwise or inappropriate acknowledges that change nevertheless, could occur, if the decision went against the arguer.

\footnotetext{
75 'But exactly because each individual case is understood within the framework of the recursive web of its own argumentation, it cannot lapse back into a vacuum or anticipate a void. It must assume that cases have been decided before and that others will follow after.' (LASS, 314)

${ }^{76}$ See, for an explanation of the temporality of law's communications in the form of what the law 'is', Nobles and Schiff, n 32 above, especially 147-163.
} 
The concept of redundancy, taken from information theory, explains why legal argumentation is not an open ended process that threatens to unravel the legal system's closure. ${ }^{77}$ The remaining functional problem is how the legal system generates variety at the level of its structures - how it generates new forms of redundancy which alter the information which it can generate. The first answer to this is simply the converse of the problem of redundancy, and one entirely familiar to lawyers. Legal argumentation is not a slot machine practice, and whilst legal arguments cannot be produced without reference to redundancy, that redundancy never shuts out new developments. In similar terms to those who criticised Dworkin's presentation of his right answer thesis in Taking Rights Seriously, there is not one right answer. Legal argumentation constantly offers choices to those who have to decide. ${ }^{78}$ Redundancy operates to make this process of selection manageable, to reduce the threat that actors who have different dispositions and experiences will be able to make changes that undermine the legal system's ability to continue its autopoiesis (to execute vast numbers of complex operations by connecting innumerable communications which have technical meanings).

The second answer to the problem of variety is present in Luhmann's discussion, referred to above, of the historical move from a jurisprudence of concepts to one of interests. Legal

\footnotetext{
${ }^{77}$ How the system 'staves off an overload of information' but at the same time, paradoxically, how 'the reduction of complexity serves to increase complexity.' (LASS, 317)

${ }^{78}$ This possibility cannot be shut out: 'Cases that require a decision are concrete cases and that means that they are different from each other ... Argumentation picks up on this provocation and transforms it into redundancy - either with a simple reference to the programmes of decision-making which have to be applied, or as a supplementation of such programmes with rules which are tested, condensed, and confirmed in relation to a greater number of possible applications. (LASS, 332)
} 
argumentation involves a constant process of comparison. The choices offered for decision include the implications for the legal system and its environment of choosing one alternative rather than another. If one focuses on the legal system, argumentation points to the difficulties, especially uncertainties, of executing its operations if a concept, rule or principle is to be altered or replaced. With the focus on the system's environment, the basis of comparison is the implications for actors, outside of the legal system, of adopting one argument (with its configuration of legal rights and obligations) rather than another. Changes in society alter the basis of comparison. Concepts that provide stability to large numbers of legal operations can lead to implications, for the environment, that appear unjust. And if society continues to change, that sense of injustice can develop; it is generated by the constant comparison of cases (which includes, in legal argumentation - if $\mathrm{x}$ is chosen, this will be the case, if $\mathrm{Y}$ is chosen this will be the case). Resistance to changes in concepts in the face of changing social conditions has led to charges such as 'formalism'. But this process of comparison, like all argumentation, involves the use of redundancy. And whilst redundancy insulates the legal system from having to respond with sensitivity to the vast number of changes that take place all the time in society ${ }^{79}$ (alongside the differences in the subjectivities of the human beings who have to undertake legal decisions), it does not exclude the possibility that changes in society will generate opportunities and pressures for change. ${ }^{80}$

\footnotetext{
79 '[Redundancy] enables indifference, both in respect of the relation between the operations of the system and, above all, in respect of the relation between the system and its environment.' (LASS, 316) ${ }^{80}$ This is not an argument that every pressure for change generated by events in law's environment will, eventually, produce responses. Some legal concepts show remarkable resistance to change, despite criticism based on their unsuitability in light of social developments. The point here is that concepts which are central to law's ability to organise its communications (which are important aspects of law's redundancy) can be expected to exhibit this resistance. Luhmann gives the example
} 


\section{Postscript}

Luhmann's version of functional analysis does not presume that the problems which have had to be solved for society to reach its current levels of complexity will continue to be solved, or solved in the same way, in the future. This sense of contingency also applies to the problems solved by legal argumentation. The existing forms of legal argumentation are not necessarily going to continue into the future, or even if they do, they are not necessarily going to provide variety with sufficient levels of redundancy. Luhmann himself was particularly concerned with the increasing tendency to base legal decisions on their expected consequences for different interests within society, by reference to a concept of balance. ${ }^{81}$ Such standards, at least by comparison with legal concepts, do not facilitate consistency. Another, related concern, was that the sheer volume of technical and specific legislation generated by modern regulatory states would create a level of contested interpretation of legal texts which would be beyond the capacity of the legal system to process through legal argumentation. ${ }^{82}$

of subjective rights, which continue to be used to organise legal communication despite social changes which depress the importance of individual actors in light of the rising importance of collective interests and public goods (LASS, 321-2).

81 'From a sociological viewpoint, it may therefore be presumed that a system which argues with an explicit interest-orientation will increase variety and therefore irritability by the environment, with corresponding internal costs'. (Luhmann 1995, n 7 above, 298)

82 'The disastrous state of modern positive law lies in the incoherence of large numbers of norms which are produced procedurally in response to a particular situation and are then lumped together in disordered heaps. No adequate means of coping with this material intellectually has been developed.' Luhmann, n 6 above, 254) 
Nevertheless, approaching legal argumentation by asking what problems it has solved, thus far, for law's evolution, and what forms have allowed it to provide its solutions, makes possible some insight into what has been achieved thus far, and what is at stake for the future. 